\title{
Community-Academic Partnerships to Promote Health Literacy and Address Social Needs Among Low-Income Families During COVID-19
}

\author{
Amier Haidar, BS ${ }^{1, *}$; Amelia Khoei, BS ${ }^{1,2, *}$; Saira E. Alex, BS ${ }^{1,2}$; Christina Blick, PhD ${ }^{3}$; \\ Elyse Lopez, BS ${ }^{2}$; Sydney Wendt, BS ${ }^{2}$; Ramesh Ghanta, BS ${ }^{2}$; Maha Almohamad, PhD ${ }^{1}$; \\ Stefanie Cousins, $\mathrm{MPH}^{3}$; Jacqueline Noyola, $\mathrm{BS}^{3}$; Jacqueline Tien, $\mathrm{BS}^{3}$; \\ Christine Markham, PhD ${ }^{1}$; Shreela V. Sharma, PhD, RD, LD ${ }^{1}$
}

\begin{abstract}
Brighter Bites is a school-based health promotion program that delivers fresh produce and nutrition education to low-income children and their families across 6 locations in the US. This article provides a perspective on how, despite coronavirus disease 2019-related school closures, Brighter Bites pivoted rapidly to collaborate with medical and public health institutions to improve health and food literacy among their families. Through these partnerships, Brighter Bites was able to rapidly provide accurate, evidence-based information related to coronavirus disease 2019 and other social needs, including food, housing, transportation, and access to health care, to help fill a needed gap in vulnerable communities.

Key Words: COVID-19, community-academic partnerships, food insecurity, health literacy (J Nutr Educ Behav. 2021;53:75-78.)

Accepted October 9, 2020. Published online October 15, 2020.
\end{abstract}

\section{INTRODUCTION}

On March 11, 2020, the World Health Organization declared the coronavirus disease 2019 (COVID-19) a pandemic. ${ }^{1}$ On March 13, 2020, the US declared a national emergency concerning the COVID-19 outbreak. ${ }^{2}$ Starting the week of March 16, 2020, through the week of March 23, 2020, states began ordering schools to close for the academic year and issuing statewide stay-at-home orders. ${ }^{3}$ The pandemic also resulted in a subsequent and ongoing exacerbation of economic, social, and health needs among families, including unemployment, food insecurity, financial insecurity, and access to health care issues. ${ }^{4,5}$
Brighter Bites is an evidence-based coordinated school-health program implemented in 6 locations in the US (Houston, Austin, Dallas, New York City, Washington, DC, and southwest Florida). ${ }^{6}$ Families enrolled in Brighter Bites receive a weekly distribution of fresh produce, plus nutrition education in school and at home. ${ }^{6}$ The program is implemented in the schools in the form of a school-based food co-op, and a total of 24,263 families were enrolled in the program in the 2019-2020 school year. However, because of the COVID-19-related school closures, regular Brighter Bites programming came to a halt. However, these same families that were enrolled in Brighter

\footnotetext{
${ }^{1}$ Michael \& Susan Dell Center for Healthy Living, UTHealth School of Public Health, University of Texas Health Science Center at Houston, Houston, TX

${ }^{2}$ Baylor College of Medicine, Houston, TX

${ }^{3}$ Brighter Bites, Houston, TX

*These authors contributed equally to this article.

Conflict of Interest Disclosure: The authors have not stated any conflicts of interest.

Address for correspondence: Amier Haidar, BS, Michael \& Susan Dell Center for Healthy Living, UTHealth School of Public Health, Texas Medical Center, Executive Offices, 1200 Pressler St, Houston, TX 77030; E-mail: amier.h.haidar@uth.tmc.edu

(C) 2020 Society for Nutrition Education and Behavior. Published by Elsevier Inc. All rights reserved.

https://doi.org/10.1016/j.jneb.2020.10.003
}

Bites remained vulnerable within many dimensions of social determinants of health during the COVID-19 pandemic. To understand these needs, Brighter Bites conducted a rapidresponse survey in April-May, 2020. Brighter Bites families responding to the survey reported a 94\% prevalence of food insecurity, whereas $76 \%$ reported being financially unstable during this time. ${ }^{7}$ In addition, the Brighter Bites team communicated, through text and phone calls, with community members and school districts who regularly receive assistance from Brighter Bites. Coordinators assessed and compiled information on potential health and social needs. The following needs were identified: (1) financial, employment assistance; (2) food assistance; (3) housing; (4) transportation; (5) legal aid; (6) COVID-19 testing centers' accessibility and availability; and (7) health care clinic access. Furthermore, there was a need for these resources to be language appropriate because of the ethnic diversity in the communities.

In response to these needs, Brighter Bites pivoted 2-fold in June, 2020 to continue programming and provide additional resources to families in need. The first pivot was regarding 
produce distribution. Brighter Bites adopted various strategies to continue produce distributions, which included (1) partnering with other nonprofit organizations including local food banks, YMCAs, etc to conduct produce distributions at community sites in lieu of schools; (2) creating for-profit partnerships with the retail industry to distribute produce vouchers to families; and (3) partnering with food growers and distributors to distribute produce boxes to families as part of the US Department of Agriculture Farmersto-Families Program. ${ }^{8}$ Details regarding these Brighter Bites food distribution strategies are presented elsewhere. ${ }^{7}$ The second pivot was regarding the community-academic partnerships with a school of public health and a medical school to develop a health literacy initiative, which are presented as part of this article. In a partnership with the University of Texas Health Science Center School of Public Health and Baylor College of Medicine Brighter Bites developed a comprehensive resource portfolio to provide accurate information to improve health literacy and meet the social needs of their families. The authors present a perspective of how nutrition-based nonprofits such as Brighter Bites can develop and implement a comprehensive health literacy portfolio of strategies beyond their regular nutrition education programming among low-income families with children during the COVID-19 pandemic. This health literacy initiative reached the network of 24,263 low-income children and their families who are participating in Brighter Bites across Houston, Dallas, Austin, New York City, Washington, DC, and southwest Florida areas.

\section{DISCUSSION}

This health literacy initiative was implemented through a partnership between the nonprofit Brighter Bites and 2 academic institutions, Baylor College of Medicine and the University of Texas Health Science Center School of Public Health. Students in public health and dual degree MD/ $\mathrm{MPH}$ programs at the schools participated in the project ( $n=7$ students).
Oversight of the students was provided by UTHealth School of Public Health epidemiology, nutrition and dietetics, and behavioral sciences faculty.

On the basis of the needs identified, the team of medical and public health students, in partnership with Brighter Bites staff, conducted an Internet-based search for information on the common needs of each of the 6 areas that Brighter Bites services. Links to online resources were compiled on the basis of the city and the category in a shared document. The students assessed each link for accessibility, timeliness, language appropriateness, and credibility and prioritized links that displayed relevant information concisely and effectively.

The Brighter Bites team reviewed the resources and created a single infographic template that students used to organize and deliver city-specific online resources in a readable, easily accessible manner (Supplementary Data). Students were tasked with personalizing the template flyer for each location served by Brighter Bites. All materials were in English, Spanish, and other languages. Leveraging the organization's preexisting dissemination platform, these flyers were used and distributed by program coordinators who directly assisted the community members.

The health literacy resources developed as part of this initiative are presented in the Table. The resources included the following: (1) preventing COVID-19; (2) mental health; (3) financial, employment assistance; (4) food assistance; (5) housing; (6) transportation; (7) legal aid; (8) COVID-19 testing centers' accessibility and availability; and (9) health care clinic access. The resources were overall and also region- and cityspecific as applicable. For example, to address the housing needs demonstrated by families, specifically regarding eviction status and rental assistance, links to city-specific eviction suspension exertions and rental assistance programs were included in the infographic sent to families.

A total of 90 multilingual resources in the form of Web links (43), infographics (41), and flyers (6) were developed and distributed to 24,363 Brighter Bites families starting March
20 through multiple modalities, including flyers provided to families at community food distributions, individual phone calls, phone texts, 12 newsletters sent through e-mails to families and community stakeholders $(n=14,261$ families and stakeholders reached), and the Brighter Bites website and Facebook page. The modality for distribution of resources was adapted for the cities depending on the public health restrictions in those cities. The Brighter Bites Facebook page increased in activity with 71, 249, and 194 new followers in March, April, and May, respectively, as well as responding to 47 messages over the course of those 3 months. The Brighter Bites Family Resources sections in English and Spanish went live on the website on May 1, 2020. Overall, the Family Resources page was the third most popular page on the Brighter Bites website during the month of May. The Family Resources section contains 4 subsections titled (1) In the Kitchen, (2) Kids Corner, (3) Connect with Us, and (4) COVID-19 Q\&A. Of the 7,499 visitors to the Brighter Bites website, Houston, New York, and Austin comprised the greatest number of users at $2,450(32 \%)$.

\section{IMPLICATIONS FOR RESEARCH AND PRACTICE}

The COVID-19 pandemic has exacerbated and highlighted the health disparities that currently exist in the US. ${ }^{9}$ During this pandemic, availability of, and accessibility to, health information is crucial, and many vulnerable populations may be further marginalized by not being able to understand and make appropriate health decisions. ${ }^{10}$ This article has an important perspective of how nonprofits such as Brighter Bites, whose core mission is to implement nutrition programming in the community, can (1) go beyond their core mission to provide critical time-sensitive information across a broad range of social needs including financial assistance, employment, housing, transportation, and health and (2) develop partnerships with academic institutions to engage medical and public health students to assist with 
Table. Summary of Resources Compiled by Students and Distributed to Brighter Bites Families

\begin{tabular}{|c|c|c|}
\hline Need & Topic & Example Resource Provided \\
\hline \multirow[t]{3}{*}{ Prevention of COVID-19 } & How COVID-19 spreads & Infographic - WHO how to wear a mask \\
\hline & Preventing COVID-19 & Infographic - WHO basic coronavirus information \\
\hline & Kids handwashing & Infographic - CDC social distancing \\
\hline $\begin{array}{l}\text { Mental health during } \\
\text { COVID-19 }\end{array}$ & Coping with stress during COVID & $\begin{array}{l}\text { Infographic }+ \text { link }- \text { CDC coping with stress during COVID } \\
\text { Infographic }+ \text { link }-\mathrm{WHO} \text { helping kids deal with stress }\end{array}$ \\
\hline \multirow{3}{*}{$\begin{array}{l}\text { Local resources (Hous- } \\
\text { ton, Dallas, Austin, } \\
\text { Washington, DC, SW } \\
\text { Florida) }\end{array}$} & COVID-19 testing sites & $\begin{array}{l}\text { Flyer with links to locations texted to families and on BB } \\
\text { website }\end{array}$ \\
\hline & Food distribution sites & \\
\hline & Food pantry sites & \\
\hline Food and nutrition & Healthy on a budget & Tip sheet \\
\hline Food insecurity & Food assistance & $\begin{array}{l}\text { Family newsletter - SNAP enrollment and pandemic SNAP } \\
\text { and P-EBT }\end{array}$ \\
\hline $\begin{array}{l}\text { Housing and public } \\
\text { utilities }\end{array}$ & Eviction status & $\begin{array}{l}\text { Links to city-specific eviction suspension extensions and } \\
\text { rental assistance }\end{array}$ \\
\hline \multirow{2}{*}{$\begin{array}{l}\text { Unemployment } \\
\text { assistance }\end{array}$} & Benefit services & Links to statewide benefits services \\
\hline & Employment options & Links to job applications \\
\hline $\begin{array}{l}\text { Health care and medi- } \\
\text { cal assistance }\end{array}$ & $\begin{array}{l}\text { Low-cost clinics } \\
\text { Modified hours }\end{array}$ & Links to city-specific updates regarding clinic availability \\
\hline Domestic violence & Crisis support during quarantine & $\begin{array}{l}\text { Family newsletter = links with available hotline phone } \\
\text { numbers }\end{array}$ \\
\hline Other social services & 211 - Local social services & \\
\hline
\end{tabular}

BB indicates Brighter Bites; CDC, Centers for Disease Control and Prevention; COVID, coronavirus disease; COVID-19, coronavirus disease 2019; P-EBT, pandemic electronic benefit transfer; SNAP, Supplemental Nutrition Assistance Program; SW, southwest; WHO, World Health Organization.

Note: For a full list of resources go to Brighter Bites website at https://www.brighterbites.org/family-resources/covid-19-qa/.

resource discovery, development, and implementation. Families that struggle with food insecurity also struggle with other social needs leading to spending trade-offs, which can greatly influence health behaviors and affect health. ${ }^{11}$ It is important, during times of crisis such as the ongoing COVID-19 pandemic, that organizations such as Brighter Bites leverage on other partnerships to provide a holistic response to meet the needs of their communities, which may go above and beyond food. Multistakeholder partnerships are a must for the success of programs such as this, not only in these times but also in others. Assessing the impact of such strategies on health literacy outcomes and meeting social needs among vulnerable families is an important avenue for future research.

In this regard, the use of this student body to continue partnering with Brighter Bites to improve resources availability and health literacy among those in need is sustainable and can be an ongoing resource for the community. Furthermore, this opportunity served the students and the academic institutions in the form of practicum, research, and publication opportunities for the students at a time during which their own clinical and public health rotations were disrupted. Finally, Brighter Bites leveraged on existing dissemination platforms such as social media, newsletters to stakeholders, and website to directly connect with families, giving the program sustainability and scalability in its dissemination methods.

\section{ACKNOWLEDGMENTS}

Funding for the study was provided by Brighter Bites through Feeding Texas and the Texas Health and Human Services Commission. The authors acknowledge the Michael \& Susan Dell Center for Healthy Living for their support on the project. Finally, the authors thank the Brighter Bites staff and the participating schools and the parents for their support on the project.

\section{SUPPLEMENTARY DATA}

Supplementary data related to this article can be found at https://doi. org/10.1016/j.jneb.2020.10.003.

\section{REFERENCES}

1. World Health Organization. General's opening remarks at the media briefing on COVID-19 - 11 March 2020. https://www.who.int/director-general/ speeches/detail/who-director-general-sopening-remarks-at-the-media-briefingon-covid-19-11-march-2020. Accessed May 27, 2020.

2. Chowell G, Mizumoto K. The COVID-19 pandemic in the USA: what might we expect. Lancet. 2020; 395:1093-1094

3. Education Week. Map: coronavirus and school closures. https://www.edweek. org/ew/section/multimedia/mapcoronavirus-and-school-closures.html. Accessed June 2, 2020.

4. Dunn CG, Kenney E, Fleischhacker SE, Bleich SN. Feeding low-income children during the COVID-19 pandemic. N Engl J Med. 2020;382:e40.

5. Nicola M, Alsafi Z, Sohrabi C, et al. The socio-economic implications of the coronavirus pandemic (COVID-19): a review. Int J Surg. 2020;78:185-193.

6. Sharma SV, Markham C, Chow J, Ranjit N, Pomeroy M, Raber M. Evaluating a school-based fruit and vegetable co-op in low-income children: a quasi- 
experimental study. Prev Med. 2016; 91:8-17.

7. Sharma SV, Chuang R, Rushing M, et al. Social determinants of healthrelated needs during COVID-19 among low-income households with children. Prev Chronic Dis. 2020;17:E119.

8. US Department of Agriculture. USDA farmers to families food box. https://www.ams.usda.gov/selling-foodto-usda/farmers-to-families-food-box. Accessed September 7, 2020.

9. Haynes N, Cooper LA, Albert MA. Association of Black Cardiologists. At the heart of the matter: unmasking and addressing the toll of COVID-19 on diverse populations. Circulation. 2020;142: 105-107.
10. Wolf MS, Serper M, Opsasnick L, et al. Awareness, attitudes, and actions related to COVID-19 among adults with chronic conditions at the onset of the U.S. outbreak: a cross-sectional survey. Ann Intern Med. 2020;173:100-109.

11. Seligman HK, Schillinger D. Hunger and socioeconomic disparities in chronic disease. N Engl J Med. 2010;363:6-9.

\section{Help JNEB Promote Your Article Via Social Media}

JNEB promotes its authors and articles on social media with each issue published. Be sure to provide a social media question and up to 5 social media accounts to help us find and promote your research on social media. 